\title{
IRRIGAÇÃO
}

\section{DISTRIBUIÇÃO ESPACIAL DO SISTEMA RADICULAR DO CAFEEIRO FERTIRRIGADO POR GOTEJAMENTO EM CAMPINAS $\left({ }^{1}\right)$}

\author{
CARLOS VINÍCIUS GARCIA BARRETO $\left({ }^{2 *}\right)$; EMÍLIO SAKAI $\left({ }^{3}\right)$, FLÁVIO BUSSMEYER ARRUDA $\left({ }^{3}\right)$; \\ EMERSON ALVES DA SILVA $\left({ }^{4}\right)$; REGINA CÉLIA DE MATOS PIRES $\left({ }^{3}\right)$
}

\begin{abstract}
RESUMO
Este estudo teve como objetivo avaliar o efeito da fertirrigação por gotejamento, utilizando-se emissores com diferentes espaçamentos $(0,50$ ou $0,80 \mathrm{~m}$ ) e profundidades de instalação (superficial, 0,10 e 0,20 m), na distribuição espacial do sistema radicular do cafeeiro. Observaram-se no cafeeiro irrigado e adubado de forma convencional diferentes condições de desenvolvimento radicular, variando conforme os tratamentos impostos. Para as plantas irrigadas por tubogotejadores com emissores espaçados a cada $0,50 \mathrm{~m}$, a profundidade radicular efetiva foi menor (média de 0,63 $\mathrm{m}$ ) do que a observada para as plantas irrigadas por emissores posicionados a cada $0,80 \mathrm{~m}$ (média de $0,70 \mathrm{~m}$ ). No manejo nutricional por fertirrigação observou-se menor desigualdade na profundidade radicular efetiva entre os tratamentos, bem como, em um aumento médio de $51,1 \%$ de densidade de raízes. Houve tendência de manutenção do volume radicular na região próxima aos emissores, enquanto nos pontos mais distantes do desenvolvimento do bulbo úmido, o crescimento radicular foi de $77 \%$. A irrigação das plantas por tubogotejadores enterrados a 0,10 m de profundidade proporcionou maior desenvolvimento radicular em resposta à fertirrigação.
\end{abstract}

Palavras-chave: raízes, irrigação, Coffea arabica.

\section{ABSTRACT \\ ROOT DISTRIBUTION OF FERTIRRIGATED COFFEE TREES IN CAMPINAS, STATE OF SÃO PAULO, BRAZIL}

This study aimed to evaluate the effect of the drip fertirrigation system, by using emitters with different arranging of spaces $(0.50$ or $0.80 \mathrm{~m}$ ) and depths of installation (superficial, 0.10 or $0.20 \mathrm{~m}$ on the ground), over the root spatial distribution of coffee tree. The coffee tree conventionally irrigated and fertilized presented different conditions of root development, varying according to the treatment imposed. For plants irrigated by emitters spaced every $0.50 \mathrm{~m}$, the effective root depth was smaller (mean of $0.63 \mathrm{~m}$ ) than that observed for plants irrigated by emitters spaced every $0.80 \mathrm{~m}$ (mean of $0.70 \mathrm{~m}$ ). The fertirrigation nutritional management allowed an uniform effective root depth among the treatments, as well as an increase of $51.1 \%$ in root density. There was a trend of maintenance of root volume in the places closer to the emitters, while in the most distant points of development of wet bulb, the growth of roots reached $77 \%$. The plants irrigated by $0.10 \mathrm{~m}$ depth emitters provided the largest root development in response to fertirrigation.

Key words: root, irrigation, Coffea arabica.

( $\left.{ }^{1}\right)$ Recebido para publicação em 7 de fevereiro de 2005 e aceito em 15 de agosto de 2006.

$\left(^{2}\right)$ Doutorando em Engenharia Agrícola, FEAGRI, UNICAMP. E-mail: carlos.barreto@agr.unicamp.br. *Autor correspondente.

$\left({ }^{3}\right)$ Centro de Pesquisa e Desenvolvimento de Ecofisiologia e Biofísica, Instituto Agronômico, Caixa Postal 28, 13012-970, Campinas (SP).

$\left({ }^{4}\right)$ Instituto de Botânica, Caixa Postal 4005, 01061-970 São Paulo (SP). 


\section{INTRODUÇÃO}

O conhecimento da distribuição espacial radicular permite maximizar oo aproveitamento de água e nutrientes pelas diversas culturas (FUGIWARA et al., 1994). Particularmente para cafeeiros, o aprofundamento radicular é uma característica fenotípica importante; plantas que expressam geneticamente tal característica são classificadas como variedades resistentes à seca. Este atributo é comum às plantas da cultivar Apoatã IAC 2258, que, de modo geral, possuem um sistema radicular bem desenvolvido (ALFONSI et al., 2003). SAKAI et al. (2000) demonstraram que plantas dessa cultivar exploram maior volume de solo $(0,65 \mathrm{~m}$ de profundidade efetiva) do que as de outras 10 cultivares avaliadas (média de $0,60 \mathrm{~m}$ ).

Embora o sistema radicular do cafeeiro tenha suas características de desenvolvimento ligadas primordialmente à genética da planta, outros fatores também podem modificar sua distribuição espacial, como a quantidade de água no solo (FrAnCO e INFORZATO, 1946) e a disponibilização de nutrientes às plantas (AMARAL, 2002).

Inforzato e ReIs (1963) salientam a necessidade de solo bem drenado para melhor desenvolvimento do sistema radicular do cafeeiro. $\mathrm{O}$ excesso de água pode ser prejudicial à planta, causando retração no desenvolvimento de suas raízes (NutMann citado por Franco e Inforzato, 1946). Por outro lado, em situações de défice hídrico, o sistema radicular do cafeeiro desenvolve-se mais do que as demais partes da planta (TomAziello et al., 2000). FRANCO e INFORZATo (1946) relataram que em solos com baixa retenção superficial de água, há um aprofundamento das raízes, demonstrando sua capacidade de adaptação diante de situações adversas. Tal característica é importante para que a planta tolere melhor os períodos mais secos (FREITAS et al., 2000).

A disponibilização de água por irrigação também pode influenciar no desenvolvimento primário e secundário do sistema radicular nas diversas camadas do solo (BARROs et al., 1997). Dentre os diversos sistemas de irrigação, o gotejamento corresponde a uma técnica que propicia maior eficiência no uso da água (BERNARDO, 1984). Segundo Philip (1997), o consumo de água pode variar de acordo com a profundidade em que o emissor foi instalado no solo. Assim, quando o emissor é instalado superficialmente, o consumo é maior nas camadas mais superficiais do solo, em virtude do poder de dessecação da atmosfera somado à extração de água pelas raízes. Por outro lado, quando o emissor é enterrado, o consumo de água é maior nas camadas mais profundas. Neste caso, a ação da gravidade conduz a água para regiões inferiores ao emissor, fazendo com que a extração pelas raízes seja maior nesse local. $\mathrm{O}$ enterrio de tubogotejadores também pode interferir no caminhamento lateral da água no solo, possivelmente no consumo de água ao longo do perfil do solo. Assim, há menores distâncias horizontais para o transporte de água, além de um aprofundamento do bulbo úmido (SouzA et al., 2003). Dessa forma, o desenvolvimento radicular dos cafeeiros irrigados pode ser condicionado às diferentes configurações dos tubogotejadores.

Outra vantagem do sistema de irrigação por gotejamento corresponde à maior eficiência na aplicação de fertilizantes quando comparado com os métodos manuais ou mecanizados de aplicação por cobertura (Antunes et al., 2001). Segundo Antunes et al. (2000), quando a técnica de irrigação é aliada à aplicação de fertilizantes, há um aumento de $35 \%$ na produtividade de raízes em relação ao uso apenas da água. Dependendo da cultivar, sob baixas condições de disponibilidade de nutrientes, pode ocorrer maior produção radicular (AMARAL, 2002). Contudo, o excesso de sais no meio de crescimento também pode reduzir a produção de matéria seca de raízes (KARASAWA et al., 2003). Para evitar problemas de salinização que causem queda na produção de raízes, o controle da concentração de sais no bulbo úmido pode ser obtido pelo manejo adequado da fertirrigação (LI et al., 2004).

O objetivo deste trabalho, portanto, foi demonstrar como o sistema de irrigação por gotejamento, sob diversas configurações de espaçamento entre emissores e diferentes profundidades de instalação, pode interferir na distribuição radicular de cafeeiros quando esses são irrigados e, posteriormente, fertirrigados.

\section{MATERIAL E MÉTODOS}

O experimento foi implantado no Centro Experimental do Instituto Agronômico (IAC), em Campinas, SP, Lat. $22^{\circ} 53^{\prime} \mathrm{S}$, Long. $47^{\circ} 05^{\prime} \mathrm{W}$, a $670 \mathrm{~m}$ de altitude. O solo da área experimental é classificado como Latossolo Vermelho eutrófico, suavemente ondulado e com face voltada para o norte. A composição granulométrica do solo da área experimental pode ser visualizada na tabela 1 . Foram realizadas análises laboratoriais de fertilidade ao longo do perfil do solo e testes de resistência à penetração no campo com penetrômetro de impacto modelo STOLF 
Planalsucar, com análise gravimétrica do perfil do solo realizada simultaneamente. Não foram encontrados impedimentos físicos ou químicos ao desenvolvimento radicular nas análises e testes realizados.

Tabela 1. Composição granulométrica do Latossolo Vermelho eutrófico da área experimental, em Campinas (SP)

\begin{tabular}{lcccc}
\hline \multirow{2}{*}{ Profundidade } & \multicolumn{4}{c}{ Granulometria } \\
\cline { 2 - 5 } & Areia grossa & Areia fina & Silte & Argila \\
\cline { 2 - 6 } $\mathrm{m}$ & 21 & 18 & 5 & 56 \\
$0,0-0,2$ & 18 & 15 & 6 & 61 \\
$0,2-0,4$ & 17 & 12 & 6 & 65 \\
$0,4-0,6$ & 16 & 13 & 6 & 65 \\
$0,6-0,8$ & 16 & 13 & 7 & 64 \\
$0,8-1,0$ & & &
\end{tabular}

A cultivar utilizada foi a Obatã IAC 1669-20 enxertada sobre o cafeeiro Apoatã (Coffea canephora cv Apoatã). As plantas foram dispostas com espaçamento de 2,5 $51 \mathrm{~m}$ entre si. Durante 5 anos (desde o plantio até outubro de 2003), as adubações foram realizadas de forma manual e aplicadas na projeção da saia das plantas, com fórmula 20-05-20, conforme exigências da cultura. Após análise do solo, foi realizada uma calagem para neutralizar o efeito acidificante das adubações.

As fertirrigações iniciaram-se em novembro de 2003, constituindo-se de cinco aplicações de uréia e cloreto de potássio, as quais foram solubilizadas e injetadas no sistema de irrigação através de uma bomba tipo venturi. O manejo das irrigações orientou-se pela evapotranspiração da cultura (média de $4 \mathrm{~mm} / \mathrm{dia}$ ), exceto nos períodos de ocorrência de precipitação pluvial.

Os tratamentos impostos utilizaram tubogotejadores com emissores de vazão de $2,3 \mathrm{~L} \mathrm{~h}^{-1}$, com espaçamento de 0,50 ou $0,80 \mathrm{~m}$ entre si e profundidades de instalação variável (superficial, 0,10 $\mathrm{m}$ ou $0,20 \mathrm{~m}$ ), perfazendo as seguintes combinações: espaçados em $0,50 \mathrm{~m}$ e instalados superficialmente (T1); espaçados em $0,50 \mathrm{~m}$ e instalados a $0,10 \mathrm{~m}$ de profundidade (T2); espaçados em $0,50 \mathrm{~m}$ e instalados a 0,20 $\mathrm{m}$ de profundidade (T3); espaçados em $0,80 \mathrm{~m}$ e instalados superficialmente (T4); espaçados em 0,80 $\mathrm{m}$ e instalados a $0,10 \mathrm{~m}$ de profundidade (T5); espaçados em $0,80 \mathrm{~m}$ e instalados a $0,20 \mathrm{~m}$ de profundidade (T6).

A amostragem das raízes e os procedimentos laboratoriais foram realizados de acordo com o recomendado por FugIWARA et al. (1994). As coletas das amostras de raízes foram feitas em locais limpos, sem plantas daninhas. Em cada época de avaliação, foram realizadas duas amostragens para cada tratamento, e para cada amostragem foi escolhida uma planta. Com o trado de raízes, as amostras foram retiradas em camadas de $0,10 \mathrm{~m}$ de profundidade até 1,50 $\mathrm{m}$, em pontos determinados a 0,40,0,80 e $1,20 \mathrm{~m}$ de distância do ramo ortotrópico principal, dos dois lados da planta e perpendicularmente à linha, e uma amostragem entre as plantas.

Os três pontos de coletas de amostra no lado da planta onde foi colocado o tubogotejador foram denominados de A, B e C, de acordo com a distância em que esses pontos estavam do ramo ortotrópico da planta $(0,40,0,80$ e $1,20 \mathrm{~m}$ respectivamente). $O$ ponto central entre as plantas foi denominado de ponto D. No lado oposto ao tubogotejador, foram estabelecidos outros três pontos, E, F e G, para aqueles situados a, respectivamente, $0,40,0,80$ e $1,20 \mathrm{~m}$ do ramo ortotrópico principal da planta (Figura 1). As coletas foram feitas em julho de 2003, antes do uso da fertirrigação, e em fevereiro de 2004, depois de ter sido iniciada. No total do experimento, coletaram-se 2.520 amostras de raízes.

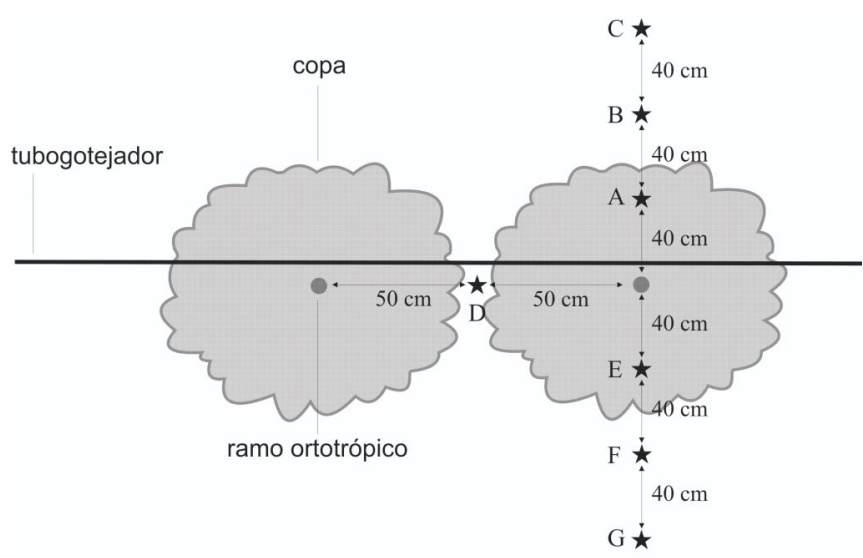

Figura 1. Posições de amostragens, em relação à linha de plantio e instalação do tubogotejador, para avaliação do sistema radicular do cafeeiro em cada um dos tratamentos.

Após a coleta, as amostras foram acondicionadas em sacos plásticos com solução de $95 \%$ de água e $5 \%$ de álcool para sua conservação. Realizaram-se, então, imersões e diluições sucessivas das amostras em água, a fim de promover a suspensão do material orgânico, inclusive das raízes. Esse material foi coletado em tamis de $0,5 \mathrm{~mm}$ de malha e colocado sobre uma folha de papel para secagem em temperatura ambiente. Em seguida, as raízes finas foram separadas, limpas e secas em estufa a $60{ }^{\circ} \mathrm{C}$ por 48 horas. 
Os valores da profundidade e da distância efetivas foram calculados no local em que havia uma concentração de $80 \%$ de raízes dentro das respectivas faixas verticais ou horizontais avaliadas. Para a avaliação da distribuição do sistema radicular, segundo o lado da amostragem, foi realizada uma análise de intervalo de confiança do desvio-padrão. Por esse processo, avaliou-se o par de pontos a 0,40 $m$ de distância da planta (A e E), de $0,80 \mathrm{~m}$ de distância (B e F) e de 1,20 m de distância (C e G). A quantidade de raízes foi medida por $\mathrm{mg} / \mathrm{cm}^{3}$, tomando-se como volume extraído de $0,00042 \mathrm{~m}^{3}$ em cada extrato do solo. A massa das raízes foi avaliada em uma balança com precisão de milésimo de grama. Além disso, o ganho na densidade radicular foi calculado pela relação entre os valores observados na primeira amostragem e aqueles da observados na segunda amostragem vezes cem.

\section{RESULTADOS E DISCUSSÃO}

Os resultados realizados pelos cálculos da profundidade radicular efetiva do cafeeiro, em julho de 2003 e fevereiro de 2004, segundo os tratamentos impostos, podem ser visualizados na tabela 2 .

Tabela 2. Profundidade efetiva média de cada tratamento seguida do erro-padrão da média nas amostragens de julho de 2003 e fevereiro de 2004, com a respectiva diferença em percentual entre ambas

\begin{tabular}{lccc}
\hline Tratamentos & $\begin{array}{c}\text { Amostragem } \\
\text { de julho } \\
\text { de } 2003\end{array}$ & $\begin{array}{c}\text { Amostragem } \\
\text { de 2004 } \\
\text { de fevereiro }\end{array}$ & $\begin{array}{c}\text { Alteração entre } \\
\text { as duas } \\
\text { amostragens }\end{array}$ \\
\cline { 2 - 4 } & \multicolumn{2}{c}{$\mathrm{m}$} & $\%$ \\
T1 & $0,54 \pm 0,07$ & $0,67 \pm 0,03$ & $+22,9$ \\
T2 & $0,65 \pm 0,07$ & $0,79 \pm 0,04$ & $+20,3$ \\
T3 & $0,69 \pm 0,05$ & $0,66 \pm 0,06$ & $-4,2$ \\
T4 & $0,69 \pm 0,05$ & $0,66 \pm 0,02$ & $-3,6$ \\
T5 & $0,73 \pm 0,05$ & $0,64 \pm 0,05$ & $-12,8$ \\
T6 & $0,67 \pm 0,06$ & $0,76 \pm 0,05$ & $+12,7$ \\
\hline
\end{tabular}

Na primeira coleta de raízes, notou-se que a profundidade radicular do cafeeiro submetido ao tratamento $\mathrm{T} 1$ foi a menor e a daquele submetido ao tratamento $\mathrm{T} 5$, a maior. A profundidade radicular efetiva média de $0,63 \mathrm{~m}$, quando os emissores estavam espaçados $0,50 \mathrm{~m}$ entre si, foi menor do que a média de $0,70 \mathrm{~m}$ de profundidade efetiva quando estavam dispostos a cada $0,80 \mathrm{~m}$ de distância. Esse comportamento aponta para uma tendência de diferenciação na distribuição das raízes quando são utilizados diferentes espaçamentos entre emissores.
Na segunda coleta de raízes, notou-se uma tendência de nivelamento da profundidade efetiva em um mesmo patamar. Nos tratamentos T1, T2 e T6, ocorreu aprofundamento das raízes de 22,9\%, 20,3\% e $12,7 \%$ respectivamente; já em $\mathrm{T} 3, \mathrm{~T} 4$ e $\mathrm{T} 5$, houve aumento de superficialidade de $4,2 \%, 3,6 \%$ e $12,8 \%$ respectivamente. Essa variação na profundidade radicular efetiva entre uma avaliação e outra ocorreu devido à mudança na forma de adubação das plantas, demonstrando a capacidade do sistema radicular do cafeeiro de se moldar conforme as condições de fertilidade do solo (FRANCO e InFORZATO, 1946). Antes da primeira amostragem, a adubação era realizada por fertilizantes aplicados sobre a superfície do solo, sob a copa do cafeeiro. Como a irrigação por gotejamento não molhava totalmente o local onde os fertilizantes foram aplicados, o transporte e caminhamento de nutrientes até as raízes foram prejudicados. Aliado a esse fato, o efeito ascendente da capilariedade retardava o aprofundamento dos nutrientes. Logo após a primeira amostragem, deu-se início à fertirrigação, possibilitando às plantas maior disponibilização de nutrientes junto à água.

Dessa forma, a fertirrigação possibilitou diferentes condições de desenvolvimento radicular, para todos os pontos avaliados. Além da fertirrigação, uma parte menor do desenvolvimento vegetativo pode ser atribuído ao avanço da idade e ao porte das plantas. Houve ganho geral do experimento de $51,1 \%$ em densidade de raízes. Entretanto, devido às diferentes configurações do sistema de irrigação, o aumento da densidade radicular não foi constante para todas as plantas (tabela 3). Os tratamentos T1, T2 e T3, tiveram, em média, crescimento da densidade radicular de $66,4 \%$, maior do que a média dos tratamentos T4, T5, T6, (35,9\%). Esse resultado indica, para o espaçamento entre emissores de $0,50 \mathrm{~m}$, um possível favorecedor do desenvolvimento radicular, possivelmente porque esse tubogotejador forme uma faixa de umidade contínua, com melhor distribuição da água ao longo da linha de gotejamento. $\mathrm{O}$ fato de o espaçamento entre emissores de $0,80 \mathrm{~m}$ propiciar menor uniformidade de distribuição ao longo da linha de gotejamento pode ter acarretado menor desenvolvimento radicular. Ademais, os tratamentos T2 e T5 tiveram um ganho médio de $76,3 \%$, valor superior às médias dos tratamentos T1 e T4, (40,7\%) e T3 e T6 (36,5\%). Essa maior evolução observada para os tratamentos com tubogotejadores enterrados a 0,10 $\mathrm{m}$ de profundidade pode indicar o favorecimento da melhor dinâmica de nutrientes no solo, se comparados àqueles com tubogotejadores colocados na superfície ou enterrados a $0,20 \mathrm{~m}$ de profundidade.

Analisando-se cada ponto separadamente, aqueles localizados mais próximos ao emissor (A e D) foram os que tiveram as menores evoluções na 
densidade de raízes, encontrando-se inclusive decréscimo de valores ao longo do tempo. Em contraste, os pontos mais distantes (E e F) tiveram os maiores ganhos de densidade radicular. Essa diferença de desenvolvimento das raízes pode estar relacionada à quantidade de água disponível ao bulbo úmido nos diferentes pontos analisados. A e D possivelmente tiveram o bulbo úmido permanentemente sob quantidades excessivas de água, causando danos às raízes e, consequentemente, desenvolvimento radicular reduzido. Por outro lado, a quantidade de água nos pontos $\mathrm{E}$ e $\mathrm{F}$ estava mais próxima da considerada ideal ou sob estresse moderado, permitindo maior desenvolvimento radicular. RENA e GuIMARÃES (2000) afirmaram que, em condições de hidratação ótima, o crescimento radicular tende a ser menor do que em condição de estresse moderado. Sob estresse, a planta produz mais ácido abcísico, reduzindo o efeito do etileno, inibidor do crescimento radicular em comprimento. Além do mais, a condição de alto teor de água no bulbo úmido deve interferir na aeração, a qual é um fator importante para respiração das raízes. Segundo esses autores, o encharcamento dificulta a passagem do etileno pelos poros do solo, que se concentra em níveis suficientes para retardar o desenvolvimento radicular.

Tabela 3. Ganho relativo da densidade de raízes para cada ponto de amostra por tratamento entre as amostras de julho de 2003 e fevereiro de 2004

\begin{tabular}{lrrrrrr}
\hline \multirow{2}{*}{ Tratamentos } & \multicolumn{6}{c}{ Pontos } \\
\cline { 2 - 7 } & \multicolumn{1}{c}{ A } & \multicolumn{1}{c}{ B } & \multicolumn{1}{c}{ D } & E & F & Média \\
\cline { 2 - 7 } T1 & 53,3 & 108,2 & 47,8 & 35,7 & 2,2 & 49,4 \\
T2 & $-35,8$ & 156,1 & 73,2 & 50,8 & 288,7 & 106,6 \\
T3 & $-19,4$ & 5,5 & 56,8 & 91,1 & 106,4 & 48,1 \\
T4 & $-29,4$ & 36,4 & $-17,2$ & 71,4 & 98,5 & 31,9 \\
T5 & 40,0 & 94,8 & 7,3 & 11,0 & 76,8 & 46,0 \\
T6 & 9,4 & 163,4 & $-39,1$ & 16,5 & $-1,7$ & 29,7 \\
\hline
\end{tabular}

Observando todo o perfil estudado, conforme o lado da amostragem em relação à linha de gotejamento, os pontos A e B tiveram menor ganho de raízes do que os pontos $E$ e F. Dentro da profundidade efetiva, a análise por intervalo de confiança do desviopadrão da média das plantas confirmou, para cada planta, essa tendência para todos os tratamentos indistintamente, exceto para o tratamento T1. Logo, na amostragem de julho de 2003, os pontos E e F tinham $19 \%$ mais amostras de raízes com densidade de raízes finas acima do intervalo de confiança do que nos pontos A e B. Na amostragem de fevereiro de 2004, essa diferença subiu para $54 \%$. O inverso foi observado para a quantidade de amostras que possuíam densidade de raízes finas abaixo do desvio padrão. Na primeira coleta, o lado dos pontos A e B tinha $33 \%$ mais pontos com densidade de raízes abaixo do desvio padrão do que o lado dos pontos $\mathrm{E}$ e F. Mantendo esta tendência, na segunda coleta de raízes, após a fertirrigação, o lado dos pontos $\mathrm{E}$ e $\mathrm{F}$ manteve $25 \%$ menos amostras em que a densidade de raízes estava abaixo do desvio-padrão.

Na tabela 4, observamos o comportamento da distribuição lateral das raízes segundo o lado da amostragem e os tratamentos impostos na primeira e na segunda coletas. A distância efetiva calculada dos cafeeiros fertirrigados foi maior no lado dos pontos A e B do que no lado oposto a eles. Esse foi o oposto ao observado na amostragem de julho de 2003. O principal motivo deste comportamento pode ser devido ao maior ganho em concentração de raízes na região mais próxima do ramo ortotrópico principal, no lado dos pontos E e F. Esse comportamento pode levar à redução da distância efetiva, pois os $80 \%$ do total de raízes tenderão a se concentrar mais proximamente ao ramo ortotrópico. Esses resultados também são concordantes com o maior ganho em concentração de raízes no lado dos pontos E e F, lado oposto ao do tubogotejador.

Tabela 4. Distância efetiva média de raízes por tratamento seguido do erro-padrão da média nas amostragens de julho de 2003 e de fevereiro de 2004, segundo o lado amostrado por tratamento

\begin{tabular}{llllll}
\hline $\begin{array}{l}\text { Trata- } \\
\text { amento }\end{array}$ & \multicolumn{2}{c}{ Amostragem de julho de 2003 } & & \multicolumn{2}{c}{ Amostragem de fevereiro de 2004 } \\
\cline { 2 - 3 } \cline { 5 - 6 } & Pontos A e B & Pontos E e F & & Pontos A e B & Pontos E e F \\
\cline { 2 - 3 } T1 & $0,64 \pm 0,04$ & $0,63 \pm 0,03$ & & $0,70 \pm 0,03$ & $0,53 \pm 0,03$ \\
T2 & $0,56 \pm 0,03$ & $0,66 \pm 0,03$ & & $0,72 \pm 0,03$ & $0,79 \pm 0,04$ \\
T3 & $0,64 \pm 0,04$ & $0,74 \pm 0,03$ & & $0,73 \pm 0,04$ & $0,70 \pm 0,03$ \\
T4 & $0,61 \pm 0,03$ & $0,60 \pm 0,03$ & & $0,69 \pm 0,03$ & $0,67 \pm 0,03$ \\
T5 & $0,67 \pm 0,02$ & $0,64 \pm 0,03$ & $0,87 \pm 0,02$ & $0,58 \pm 0,03$ \\
T6 & $0,50 \pm 0,03$ & $0,60 \pm 0,04$ & $0,85 \pm 0,03$ & $0,50 \pm 0,03$ \\
\hline
\end{tabular}

Pontos A e B, E e F: referentes ao lado de amostragens, segundo figura 1 .

Nos pontos C e G, observaram-se resultados discrepantes dos demais pontos. Contudo, a representatividade desses pontos juntos na massa total de raízes é inexpressiva. Esse fato tende a mascarar resultados extrapolados para toda a planta. As médias de representatividade dos dois pontos juntos na primeira e na segunda amostragem perfazia $7,7 \%$ e $11,8 \%$. Essa baixa representatividade leva a distorções nos resultados de profundidade efetiva, pois a distribuição ao longo da profundidade é muito desuniforme. Os cálculos da concentração de $80 \%$ da zona radicular em distância concordam com essa afirmação. 
Os resultados desse cálculo estão apresentados na tabela 4 , onde se observa que a distância efetiva de raízes em média não ultrapassou os $0,80 \mathrm{~m}$. Esse comportamento coincide com o observado por INFORZATO e REIS (1963) que afirmaram que o sistema radicular dos cafeeiros das variedades Mundo Novo e Boubon Amarelo, em sua grande maioria, não ultrapassou $0,75 \mathrm{~m}$ de distância do ramo ortotrópico principal. Conforme se observa na tabela 5, em T1, no lado dos pontos A e B dentro da profundidade efetiva houve ganho de $29,7 \%$ em distância efetiva a partir do ramo ortotrópico, e no lado oposto, houve redução de $2,4 \%$. Já no tratamento $\mathrm{T} 2$, houve aumentos em distância efetiva para ambos os lados; contudo, no lado dos pontos A e B, houve maior ganho em distância efetiva dentro da profundidade efetiva, $38,2 \%$, contra $20 \%$ no lado dos pontos E e F. No tratamento T3, dentro da profundidade efetiva no lado dos pontos $\mathrm{A}$ e B, houve acréscimo de 20,5\% na distância efetiva das raízes, também maior quando comparado com o lado oposto, $12,4 \%$. O tratamento T4 propiciou aumento de $23,6 \%$ na distância efetiva no lado dos pontos A e B dentro da profundidade efetiva, contra o aumento de $12,3 \%$ do lado oposto na mesma faixa de profundidade. $\mathrm{O}$ tratamento $\mathrm{T} 5$ permitiu aumento na distância efetiva em $28,5 \%$ no lado dos pontos $\mathrm{A}$ e $\mathrm{B}$, ao passo que o lado oposto teve $6,1 \%$. O tratamento $\mathrm{T} 6$ gerou aumento na distância efetiva de $68,8 \%$, no lado dos pontos A e B, contra uma redução na distância efetiva de $8,9 \%$ no lado oposto.

Observando-se a tabela 5, para o lado dos pontos A e B, o aumento da distância efetiva dentro da profundidade efetiva foi maior do que ao longo de todo o perfil; além disso, tendeu a ocorrer evolução negativa no lado dos pontos E e F. Houve relação entre o ganho de densidade radicular no lado oposto ao do tubogotejador (E e F) e as menores distâncias nas quais se concentram $80 \%$ da zona radicular, posto que, a menor densidade radicular é a responsável pela necessidade de se somar maior quantidade de raízes, aumentado a distância necessária para a totalização dos $80 \%$ das raízes. O oposto parece ser verdadeiro; maiores densidades de raízes próximas ao ramo ortotrópico principal implicam em menor necessidade de soma das raízes em regiões de menor densidade delas, geralmente a maiores distâncias da planta. $\mathrm{O}$ fato de existir variação no desenvolvimento das raízes concorda com o afirmado por FRANCO e INFORZATO (1946), que observaram variação na sua distribuição em solos com diferentes condições edáficas. O sistema de gotejamento, porém, imprime grande variação nas condições de umidade e nutricionais dentro do mesmo solo (BERNARDO, 1984; ZuR, 1996), interferindo no desenvolvimento radicular.
Tabela 5. Variação na distância efetiva média das raízes relativa à diferença dos valores da primeira e segunda coleta para os pontos A e B para os pontos E e F, dentro da profundidade efetiva (P.E.) e ao longo de toda a profundidade estudada $(1,5 \mathrm{~m})$

\begin{tabular}{lccccc}
\hline \multirow{2}{*}{ Tratamento } & \multicolumn{2}{c}{ Lado dos pontos A e B } & \multicolumn{2}{c}{ Lado dos pontos E e F } \\
\cline { 2 - 3 } \cline { 5 - 6 } & P.E. & até $1,5 \mathrm{~m}$ & & P.E. & até $1,5 \mathrm{~m}$ \\
\cline { 2 - 3 } T1 & 29,7 & 20,6 & $-02,4$ & $-11,7$ \\
T2 & 38,2 & 30,8 & 20,0 & 24,6 \\
T3 & 20,5 & 18,3 & 12,4 & $-02,8$ \\
T4 & 23,6 & 24,0 & & 12,3 & 16,2 \\
T5 & 28,5 & 32,6 & 06,1 & $-5,1$ \\
T6 & 68,8 & 77,5 & $-08,9$ & $-7,9$ \\
\hline
\end{tabular}

\section{CONCLUSÕES}

1. No cafeeiro irrigado e adubado de forma convencional observou-se que nos tratamentos com emissores espaçados a $0,50 \mathrm{~m}$, a profundidade efetiva média foi de $0,63 \mathrm{~m}$. Por outro lado, os tratamentos com emissores espaçados a $0,80 \mathrm{~m}$ a profundidade atingiu $0,70 \mathrm{~m}$.

2. A fertirrigação reduziu a desigualdade de profundidade efetiva entre os tratamentos, porém, o maior desenvolvimento radicular ocorreu quando os emissores estavam espaçados a cada $0,50 \mathrm{~m}$ de distância e enterrados a 0,10 m de profundidade.

\section{REFERÊNCIAS}

ALFONSI, E.L.; FAHL, J.I.; CARELLI, M.L.C. Estudo fisiológico da parte aérea e do sistema radicular e nutrição mineral de quatro espécies de Coffea e um híbrido natural, visando conhecer seus potenciais para utilização como porta-enxertos. In: SIMPÓSIO DE PESQUISA DOS CAFÉS DO BRASIL E WORKSHOP INTERNACIONAL DE CAFÉ \& SAÚDE, 3, 2003, Porto Seguro. Anais... Brasília: Embrapa Café, 2003. p. 68.

AMARAL, J.F.T. Eficiência de produção de raízes, absorção, translocação e utilização de nutrientes em cultivares de café arábica. 2002. 97 f. Tese (Doutorado em Fitotecnia) Universidade Federal de Viçosa.

ANTUNES, R.C.B.; MANTOVANI, E.C.;SOARES, A.R.; RENA, A.B.; BONOMO, R. Área de observação e pesquisa em cafeicultura irrigada na região das vertentes de Minas Gerais: Resultados de 1988 / 2000. In: SIMPÓSIO DE PESQUISA DE CAFÉS DO BRASIL, 1, 2000, Poços de Caldas. Anais. Brasília: Embrapa Café, 2000. v.2, p.823-826.

ANTUNES, R.C.B.; RENA, A.B.; MANTOVANI, E.C. Fertirrigação na cultura do cafeeiro arábica. Viçosa: Associação dos Engenheiros Agrícolas de Minas Gerais. Universidade Federal de Viçosa, 2001. 39 p. 
BARROS, R.S.; MOTA, J.W. DA S.; DA MATTA, F.M.; MAESTRI, M. Decline of vegetative growth in Coffea arabica in relation to leaf temperature, water potential and stomatal condutance. Field Crops Research, Amsterdam, v.54, August, p. 65-72, , 1997.

BERNARDO, S. Irrigação por gotejamento. In: BERNARDO, S. Manual de irrigação. 3 ed. Viçosa: Imprensa Universitária, 1984. p. 389-392.

FRANCO, C.M.; INFORZATO, R. O sistema radicular do cafeeiro nos principais tipos de solo do estado de São Paulo. Bragantia, Campinas, v.6, n.9, p.443-458, 1946.

FREITAS, R.B.;OLIVEIRA, L.E.M.;SOARES, A.M.; FARIA, M.A.; DELÚ FILHO, N. Comportamento fisiológico de dois cultivares de Coffea arabica L. submetidos a duas condições de disponibilidade hídrica. In: SIMPÓSIO DE PESQUISA DOS CAFÉS DO BRASIL, 1, 2000, Poços de Caldas. Anais. Brasília: Embrapa Café, 2000. v.2, p. 917-919.

FUGIWARA, M.; KURACHI, S.A.H.; ARRUDA, F.B.; PIRES, R.C.M.; SAKAI, E. A técnica de estudo de raízes pelo método do trado. Campinas: Instituto Agronômico, 1994. 9 p. (Boletim Técnico IAC $\mathrm{n}^{\mathrm{o}}$ 153)

INFORZATO, R.; REIS, A.J. Estudo comparativo do sistema radicular dos cafeeiros Bourbon Amarelo e Mundo Novo. Bragantia, Campinas, v.22, n.59, p.742-750, 1963.

KARASAWA, S.; EGUCHI, E. S.; IGARASHI, G. DA S.; MIRANDA, J. H. DE; DUARTE, S. N. Salinidade na água de irrigação no desenvolvimento radicular da muda do cafeeiro. In: SIMPÓSIO DE PESQUISA DOS CAFÉS DO BRASIL E WORKSHOP INTERNACIONAL DE CAFÉ \& SAÚDE, 3., 2003, Porto Seguro. Anais... Brasília: Embrapa Café, 2003. p. 148.

LI, J., ZHANG, J.; RAO, M. Wetting patterns nitrogen distributions as affected by fertigation strategies from a surface point source. Agricultural Water Management. Amsterdam, v.67, February, p. 89-104, 2004.
PHILIP, J.R. Effect of root water extraction on weted regions from continuous irrigation sources. Irrigation Science, Heidelberg, v.17, May, p. 127-135, 1997.

RENA, A.B.; GUIMARÃES, P.T.G. Sistema Radicular do Cafeeiro: Estrutura, Distribuição, Atividade e Fatores que o influenciam. Belo Horizonte: Empresa de Pesquisa Agropecuária de Minas Gerais. 2000, 80 p.

SAKAI, E.; GALLO, P.B.; FAHL, J.I.; ARRUDA, F.B.; IAFFE, A.; PIRES, R.C.M.; CALHEIROS, R. O. Efeito do desenvolvimento do sistema radicular na produtividade do cafeeiro enxertado em Mococa, SP. In: SIMPÓSIO DE PESQUISA DOS CAFÉS DO BRASIL, 1, 2000, Poços de Caldas. Anais... Brasília: Embrapa Café, 2000. v.1, p. 58-61.

SOUZA, C.F. A utilização da reflectometria no domínio do tempo (TDR) na modelagem do bulbo molhado do solo irrigado por gotejamento. 2002. $115 \mathrm{f}$. Tese (Doutorado em Engenharia Agrícola) - Faculdade de Engenharia Agrícola, Campinas.

SOUZA, E.A.; COELHO E.F.; PAZ V.P.S.; DA SILVA, T.S.M. Distribuição da umidade num Latossolo irrigado por gotejamento superficial e subsuperficial e enterrado, com uso de TDR. In: CONGRESSO NACIONAL DE IRRIGAÇÃO E DRENAGEM, 13., 2003, Juazeiro. Anais... Viçosa: Associação Brasileira de Irrigação e Drenagem, 2003. p.?

THOMAZIELLO, R.A.; FAZUOLI, L.C.; PEZZOPANE, J.R.M.; FAHL, F.I.; CARELLI, M.L.C. Café arábica: cultura e técnicas de produção, Campinas: Instituto Agronômico, 2000. 82 p. (Boletim técnico, IAC n. ${ }^{\circ} 187$ )

ZUR, B. Wetted soil volume as a design objective in trickle irrigation. Irrigation Science, New York, v.16, February, p. 101-105, 1996. 